Editorial

\title{
Heat Transfer, Refrigeration and Heat Pumps
}

\author{
Moonis R. Ally *(D) and Brian Fricke \\ Buildings and Transportation Science Division, Oak Ridge National Laboratory, Oak Ridge, TN 37830, USA; \\ frickeba@ornl.gov \\ * Correspondence: allymr@ornl.gov; Tel.: +1-865-576-8003
}

Citation: Ally, M.R.; Fricke, B. Heat Transfer, Refrigeration and Heat Pumps. Energies 2021, 14, 7988. https://doi.org/10.3390/en14237988

Received: 22 November 2021 Accepted: 25 November 2021 Published: 30 November 2021

Publisher's Note: MDPI stays neutral with regard to jurisdictional claims in published maps and institutional affiliations.

Copyright: (c) 2021 by the authors. Licensee MDPI, Basel, Switzerland. This article is an open access article distributed under the terms and conditions of the Creative Commons Attribution (CC BY) license (https:// creativecommons.org/licenses/by/ $4.0 /)$.
The Special Issue entitled "Heat Transfer, Refrigeration and heat Pumps" accepted papers covering a wide range of topics related to heat pumps, thermal energy storage, and low-Global Warming Potential (GWP) alternative refrigerants. Heat pumps play a vital role in providing space conditioning and water heating while utilizing the energy of the environment. Since heat pumps use renewable thermal energy from the environs to provide the desired utility, they contribute to the portfolio of technologies that mitigate carbon footprint. The heat pump may be considered a truly renewable technology if the electricity it uses comes entirely from a renewable source. More accurately, a heat pump is a "low carbon technology". These perspectives make heat pumps an indispensable option for the future in order to reduce the nocuous human impact on the environment. More efficient heat pumping technologies are being developed for the residential, commercial, and industrial sectors of the economy. Another R\&D thrust is heat pumps for cold climates. Hardware components, use of low-GWP refrigerants, and identification of systemic inefficiencies are active research areas. This article is a synopsis of the papers submitted to the Special Issue.

As Guest Editor of this Special Issue, the papers selected represented those that were at the cutting edge of technological development, whose potential for addressing energy efficiency, and the implications for Climate Change, would have a lasting impact. In this sense, the papers were pushing the technological envelope. From a total of 11 submissions, seven were accepted and the remaining four were rejected.

In the next section, we provide a brief review of the seven published papers [1-7] and their potential scope of application.

An overview of the selected papers covered the following technical area:

- Superheat control using virtual sensors intrinsic within the heat pump system;

- Replacing high-GWP refrigerants with low-GWP refrigerants without compromising performance or changing the hardware;

- Alternate geometries for thermoelectric modules to improve cooling;

- Using heat pumps in large, complex industrial processes to further enhance pinch technology;

- Using carbon dioxide (GWP $=1$ ) as a refrigerant to reduce leakage of high-GWP refrigerants while simultaneously improving capacity and performance;

- Thermal energy storage through hot water storage in residential applications;

- Methods to reduce hydrocarbon charge in HVAC heat exchangers.

The paper by Sun et al. [1] describes the option of using a virtual sensor as a costeffective and convenient way of estimating the pressure to maintain electronic expansion valve (EXV) superheat control instead of using both temperature and pressure sensors, as in conventional HVAC systems. The paper concludes that the pressure sensor can be substituted with a virtual pressure sensor without compromising the system's operational needs while eliminating the need for a separate sensor. Additional work on methods for automatically identifying sensor faults and continuously calibrating the virtual sensor are short-term R\&D needs. 
Shen and Ally [2] discuss drop-in replacement of an existing high-GWP refrigerant (R-410A) with alternate lower-GWP refrigerants without sacrificing performance. The focus of their paper is to replace the exclusive use of R-410A which has a GWP of 2100. The authors analyze the performance of four alternatives (R32, R452B, R454B, and R466A) relative to the conventional $\mathrm{R}-410 \mathrm{~A}$ and draw conclusions on the relative performances for providing heating in cold climates based on the Air-Conditioning, Heating, and Refrigeration Institute (AHRI) 210/240 standard for two-speed heat pumps. Systemic inefficiency is identified by exergy analysis. The results clearly show the potential benefits of using the alternate lower-GWP refrigerants and the improvements in specific hardware components (through exergy analysis) to make heat pumping even more energy efficient.

Thermoelectric modules are customarily arranged in a rectangular pattern. Whether or not other geometries may be advantageous is an open question. The paper by Lu et al. [3] examined a trapezoidal arrangement with a non-constant cross-sectional area. The performance of this arrangement was computed using finite element analysis. By adjusting the trapezoidal dimensions, the thermoelectric chip may be operated at lower temperatures and less thermal stress.

Schlosser et al. [4] analyzed the benefits that heat pumps may bring to complex industrial processes that have multiple heating and cooling streams that require energy transactions. Managing these thermal streams has a direct bearing on energy and environmental costs. Their paper is similar to the famed Pinch Analysis that evolved primarily in the 1980s, except that the authors call it Bridge Analysis. The approach is to match simultaneous cooling and heating streams as much as possible and the balance of thermal needs (cooling or heating) may be met with efficient heat pumps.

In supermarket and grocery stores, refrigeration can use almost 40 percent of the total energy. Improving the energy efficiency of commercial refrigeration equipment like restaurant-size refrigerators or the deli cases at the local grocery stores benefits the businesses and reduces energy consumption and greenhouse gases emissions. Elatar et al. [5] discuss that carbon dioxide is a promising refrigerant for commercial refrigeration since it is non-toxic, non-flammable, has a GWP of one, and fits well in terms of its applications in supermarkets and warehouses. The challenges associated with carbon dioxide are its low critical temperature, high operating pressures and higher expansion leases that mitigate system performance at warmer ambient temperatures. To recover these losses, a pressure exchange process between the low- and high-pressure sides of the vapor compression cycle was examined using computational fluid dynamics. The prototype pressure exchanger is based on technology used in reverse osmosis and desalination systems. The paper concluded that the concept of exchanging momentum energy between the low-and highpressure flows in a trans-critical carbon dioxide refrigeration cycle is capable of increasing cycle performance; however, depending on the flow rates, exergy losses may increase by up to 15 percent relative to the highest efficiency obtained in the simulations.

Water heaters represent one option for convenient thermal energy storage in residential or commercial applications for both hot water and chilled water storage. However, their energy efficiency depends on system components as well as internal water stratification in the storage tank during water draws. The paper by Rendall et al. [6] examined the impact of temperature stratification based on a 1D model because such simulations are not as computationally intense as $2 \mathrm{D}$ or 3D models. To capture the essential physics of the problem and perform a comparative study, the authors included pure plug flow, plug flow with axial conduction, and two convection eddy diffusivity models. Comparing the results of these simulations against experimental data, showed that inclusion of the convection eddy diffusion effect gave the best agreement with experimental data. The model effectively captured stratification levels for water draws with $2100<\operatorname{Re}<10,000$, typical of entering and exiting water flow rates in households.

The paper by Allymehr et al. [7] addresses the issue of reducing propane charge levels in HVAC systems. Two systems are compared: the first is a direct heat pump, with fin-andtube heat exchangers, and the second is an indirect system, with plate heat exchangers with 
an additional brine-to-air heat exchanger. Each system had a $5 \mathrm{~kW}$ design cooling capacity in summer and an $8 \mathrm{~kW}$ design heating capacity in winter. Results showed that the propane charge was reduced by $22 \%$ in the direct heat pump system by using micro-finned tubes and a greater charge reduction of $66 \%$ occurred in the indirect heat pump with specially designed brazed plate heat exchangers with minimum internal volume instead of using normal plate heat exchangers. In the simulations, the effects of refrigerant maldistribution or inclusion of a liquid line were not considered but further experimental investigation is justified for adoption of low-GWP hydrocarbon refrigerants.

Author Contributions: Both authors contributed towards interpreting the technical content and writing the paper. All authors have read and agreed to the published version of the manuscript.

Funding: This research received no external funding.

Conflicts of Interest: The authors declare no conflict of interest.

\section{References}

1. Sun, J.; Dong, J.; Shen, B.; Li, W. Virtual Pressure Sensor for Electronic Expansion Valve Control in a Vapor Compression Refrigeration System. Energies 2020, 13, 4917. [CrossRef]

2. Shen, B.; Ally, M.R. Energy and Exergy Analysis of Low-Global Warming Potential Refrigerants as Replacement for R410A in Two-Speed Heat Pumps for Cold Climates. Energies 2020, 13, 5666. [CrossRef]

3. Lu, T.; Li, Y.; Zhang, J.; Ning, P.; Niu, P. Cooling and Mechanical Performance Analysis of a Trapezoidal Thermoelectric Cooler with Variable Cross-Section. Energies 2020, 13, 6070. [CrossRef]

4. Schlosser, F.; Wiebe, H.; Walmsley, T.G.; Atkins, M.J.; Walmsley, M.R.W.; Hesselbach, J. Heat Pump Bridge Analysis Using the Modified Energy Transfer Diagram. Energies 2021, 14, 137. [CrossRef]

5. Elatar, A.; Fricke, B.; Sharma, V.; Nawaz, K. Pressure Exchanger for Energy Recovery in a Trans-Critical $\mathrm{CO}_{2}$ Refrigeration System. Energies 2021, 14, 1754. [CrossRef]

6. Rendall, J.; Karg Bulnes, F.; Gluesenkamp, K.; Abu-Heiba, A.; Worek, W.; Nawaz, K. A Flow Rate Dependent 1D Model for Thermally Stratified Hot-Water Energy Storage. Energies 2021, 14, 2611. [CrossRef]

7. Allymehr, E.; Skaugen, G.; Will, T.; Pardiñas, Á.Á.; Eikevik, T.M.; Hafner, A.; Schnabel, L. Numerical Study of Hydrocarbon Charge Reduction Methods in HVAC Heat Exchangers. Energies 2021, 14, 4480. [CrossRef] 